\title{
Developing and testing a computer vision method to quantify 3D movements of bottom-set gillnets on the seabed
}

\author{
Savina, Esther; Krag, Ludvig Ahm; Madsen, Niels
}

Published in:

ICES Journal of Marine Science

Link to article, DOI:

10.1093/icesjms/fsx194

Publication date:

2018

Document Version

Peer reviewed version

Link back to DTU Orbit

Citation (APA):

Savina, E., Krag, L. A., \& Madsen, N. (2018). Developing and testing a computer vision method to quantify 3D movements of bottom-set gillnets on the seabed. ICES Journal of Marine Science, 75(2), 814-824.

https://doi.org/10.1093/icesjms/fsx194

\section{General rights}

Copyright and moral rights for the publications made accessible in the public portal are retained by the authors and/or other copyright owners and it is a condition of accessing publications that users recognise and abide by the legal requirements associated with these rights.

- Users may download and print one copy of any publication from the public portal for the purpose of private study or research.

- You may not further distribute the material or use it for any profit-making activity or commercial gain

- You may freely distribute the URL identifying the publication in the public portal 


\section{Developing and testing a computer vision method to quantify 3D movements of bottom-set gillnets on the seabed}

Esther Savina ${ }^{\mathrm{a}}$, Ludvig Ahm Krag ${ }^{\mathrm{a}}$, Niels Madsen ${ }^{\mathrm{a}^{*}}$

a Technical University of Denmark, National Institute of Aquatic Resources, Willemoesvej 2, 9850 Hirtshals, Denmark

* Section of Biology and Environmental Science, Department of Chemistry and Bioscience, Aalborg

University, Fredrik Bajers Vej 7, 9220 Aalborg, Denmark

CORRESPONDING AUTHOR

Esther Savina, esav@aqua.dtu.dk, +45 35883202

Technical University of Denmark, National Institute of Aquatic Resources, Willemoesvej 2, 9850 Hirtshals, Denmark

KEYWORDS:

Coastal waters; Environmental impact; Fishing gear; Gillnet; Habitat; Stereo vision 


\section{HIGHLIGHTS}

- A stereo imaging method was adapted to quantify in situ fishing gear habitat effect.

- The movement of the leadline of light and heavy bottom gillnets on sand was assessed.

- The direct mechanical damage to the seabed (penetration) of gillnets was minimal.

- The sweeping movements were higher than estimated by experts, up to $2 \mathrm{~m}$.

- Light nets were moving significantly more than heavy ones.

\section{ABSTRACT}

1 Gillnets are one of the most widely used fishing gears, but there is limited knowledge about

2 their habitat effects, partly due to the lack of methodology to quantify such effects. A stereo

3 imaging method was identified and adapted to quantify the dynamic behavior of gillnets in-

4 situ. Two cameras took synchronized images of the gear from slightly different perspectives,

5 allowing to estimate the distance from the observation unit to the gear such as in the human 3D

6 vision. The sweeping motion on the seabed and the penetration into the sediment of the leadline

7 of light and heavy commercial bottom gillnets deployed in sandy habitats in the Danish coastal

8 plaice fishery were assessed. The direct physical disruption of the seabed was minimal as the

9 leadline was not penetrating into the seabed. Direct damage to the benthos could however

10 originate from the sweeping movements of the nets, which were found to be higher than usually

11 estimated by experts, up to about $2 \mathrm{~m}$. The sweeping movements were for the most part in the 12 order of magnitude of $10 \mathrm{~cm}$, and resulted in a total swept area per fishing operation lower than 13 any of the hourly swept area estimated for active fishing gears. Whereas the general perception

14 is that heavy gears are more destructive to the habitat, light nets were moving significantly 15 more than heavy ones. The established methodology could be further applied to assess gear 16 dynamic behavior in-situ of other static gears. 


\section{Introduction}

18 Ecosystem effects of fisheries and in particular habitat damage is of high interest in an

19 Ecosystem Approach to Fisheries as some fishing gears can remove or damage habitat forming

20 structures, potentially reducing the complexity, diversity and productivity of benthic

21 environments (Jennings and Kaiser, 1998; Kaiser et al., 2000; Kaiser et al., 2002; Hermsen et

22 al., 2003; Grabowski et al., 2014). The Marine Strategy Framework Directive defines seabed

23 integrity as one of the descriptors required by the European Union member states to ensure

24 Good Ecological Status (E.C., 2008). Methods are being developed for assessing the

25 responsiveness of different seabed habitats to fishing activities, resulting in habitat sensitivity

26 maps, which can be used in marine spatial planning (Eno et al., 2013). Eco-labelling initiatives

27 have started to take gear impacts on habitats into account in their assessments (Olson et al.,

28 2014). In this context, providing documentation for the habitat effect of fishing gears is of prime

29 importance, especially for small-scale fisheries where maintaining profitability may be

30 challenging and where there are benefits to keeping fishing in traditional fishing grounds,

31 including sensitive areas, or where higher prices could be obtained from eco-labelling.

32 Gillnets stand as the fourth most important general gear type (out of 8) contributing to the

33 global marine catches (in weight, based on data from 1950 to 2001, Watson et al., 2006). About

$3440 \%$ of the European fishing vessels belong to the small-scale bottom-set gillnets fleet (by

35 number, as of December 2016), with 33644 active vessels under 12m with set gillnets (GNS) as

36 main gear, and up to $80 \%$ in Denmark for example (by number, with 1838 active vessels under

37 12m with GNS as main gear as of December 2016) (E.C., 2016). It is generally assumed that

38 habitat impacts of fixed gears are lower than those of mobile gears (Suuronen et al., 2012;

39 Grabowski et al., 2014). However, these conclusions are based on few experimental studies. For 
example, there were only five studies regarding fixed gears, i.e., longlines, traps and gillnets, out

41 of 97 used for the latest assessment in New England, US (Grabowski et al., 2014). Taking a

42 closer look at bottom gillnets, the lack of studies regarding habitat impact might be attributed to

43 the general assumption of negligible effects (Uhlmann and Broadhurst, 2013). However, after in

44 situ observation at two rocky reefs, Shester and Micheli (2011) identified set gillnets as a

45 priority conservation concern due to their potential to damage habitat-forming species. In the

46 Welsh part of the Irish Sea, Eno et al. (2013) assessed nets sensitivity as high to medium for

47 high to low fishing intensities in 8 habitats out of 31 , mostly rock with associated branching

48 species such as kelp, seaweeds or maerl beds. There is no direct evidence of potential effect for

49 many of the current habitat-gear combinations, and the degree to which fixed gears drift on the

50 bottom has to be quantified for the different bottom types (Eno et al., 2013; Grabowski et al.,

$512014)$.

52 There is limited knowledge about the habitat effects of bottom gillnets partly due to historical

53 focus on active gears, but also because data collection and analysis calls for the development of

54 appropriate innovative assessment methodologies. Several optical or acoustic techniques have

55 been developed as complementary tools to assess the impact of mobile gears on the seabed

56 (Smith et al., 2003; Humborstad et al., 2004; O’Neill et al., 2009; Lucchetti and Sala, 2012;

57 Depestele et al., 2016). However, not all techniques provide a spatial resolution fine enough to

58 assess bottom gillnets. Others are restrictive in sampling duration. Eventually, not all techniques

59 can easily and safely be operated around bottom gillnets, prone to entanglement. Video offers

60 more precision and less bias than direct visual observation, as it is possible to view each

61 recording repeatedly or at lower speed (Neuswanger et al., 2016). Nevertheless, the value of a

62 video recording as informative data also depends on the ability to extract relevant measurements 
63 (Struthers et al., 2015; Neuswanger et al., 2016). Waterproof action cameras are now commonly

64 available tools to deliver cost efficient high-definition underwater video recordings (Struthers et 65 al., 2015) using simple deployment platforms.

66 In bottom-set gillnets, the gear components in contact with the seabed are the leadline, the

67 anchors and the bridle lines (connecting the anchors to the netting). Gillnets may be dragged on

68 the seabed and become tangled in bottom features as the gear moves with the water flow while

69 fully deployed on the seabed. Gillnets may also be snagged on benthic structures or organisms

70 during retrieval of the gear (Shester and Micheli, 2011). The gear characteristics and rigging

71 specifications play a key role in the net behavior, and therefore its potential seabed effects. The

72 net is spread vertically by the buoyancy of floats on the headline and weight in the leadline

73 (Takagi et al., 2007; He and Pol, 2010). The gear is usually moored at both ends with weights or

74 anchors, which can cause vertical and horizontal deformation of the netting (Shimizu et al.,

75 2007; He and Pol, 2010). Water flow pushes the netting to incline and bulge out of the vertical

76 plane (Stewart, 1988; Takagi et al., 2007). Shimizu et al. (2007) calculated that the leadline

77 would slide across the sea bottom if the force acting on the leadline is larger than the coefficient

78 of static friction, but sliding motions of bottom gill nets during fishing have not been directly

79 observed in any study to our knowledge.

80 The aim of the study was to identify, adapt, test and use a suitable methodology for assessing

81 the dynamic behavior of the leadline of bottom gillnets, i.e., the sweeping motion on the seabed

82 and the penetration into the sediment. An in-situ pilot experiment using stereo imaging was

83 carried out in the Danish gillnet coastal plaice fishery.

\section{2. Material and methods}




\section{Stereo imaging: general principle and quantitative measurements with VidSync}

86 Stereo imaging consists of two cameras taking synchronized images of a scene from slightly

87 different perspectives, or vantage points, which then allow to estimate the distance to an object

88 such as in the human 3D vision. If an object is uniquely identified in both images and if the

89 translation and rotation of one camera relative to the second is known, it is then possible to

90 estimate the location of the object in 3D space (Schmidt and Rzhanov, 2012).

91 The free open-source Mac application VidSync (www.vidsync.org) was developed based on

92 the OpenCV library computer vision algorithms by Neuswanger et al. (2016) to process stereo

93 video recordings. The mathematical calculations of 3D measurements and their application in

94 VidSync are detailed by Neuswanger et al. (2016).

95 Before the proper calculation of the 3D coordinates of a point, one has to correct for lens

96 distortion and establish the perspective of each camera. Lens distortion is induced by the fisheye

97 lens of the camera, meant to widen its angle of view, but particularly pronounced when the

98 camera records underwater through housing and prone to bias calculations. Correction factors,

99 or distortion parameters, can be found by locating nodes on a chessboard pattern or calibration

100 frame and arranging them into straight lines. The same chessboard pattern can be used to

101 calculate the projection matrices for each camera by matching the known physical 2D node

102 coordinates on each face of the calibration frame with screen coordinates, which are recorded in

103 VidSync by clicking on the centre of each node on the video recordings.

104 The 3D coordinates of a point are calculated in VidSync by iterative triangulation, aiming at

105 establishing two lines-of-sight that approximately intersect at the point of interest, which is

106 undertaken by clicking on the different points of the leadline, on each video recording. The 
107 calibration frame is the only source of information on the scaling of distances from which

108 VidSync reconstructs a 3D space from the 2D video recordings.

109 Pilot experiment: location of the sea trials, net type and gear specifications

110 The pilot experiment took place in ICES area IIIa (Kattegat) off the coast of Northern

111 Denmark aboard a small research vessel $(5 \mathrm{~m})$ on September 10th 2015. Because of its

112 importance regarding Danish traditional commercial fishing grounds, and as the probability that

113 the leadline would slide across the sea bottom is higher for smooth surfaces than for rough

114 surfaces (Shimizu et al., 2007), the experiment took place on sandy bottom. Nets were deployed

115 in shallow waters, i.e., 1.5 to $3 \mathrm{~m}$ depth, to operate the observation units as best as possible in

116 relation to the deployed gillnets in the relatively turbid waters. Our experimental conditions

117 were at the lower depth range of commercial practices, but many coastal vessels participating in

118 the gillnet plaice fishery, usually fish between 2 and $8 \mathrm{~m}$ in the summer and autumn. All

119 observations were made away from the surf zone in calm weather to limit the influence of

120 waves.

121 Two different types of commercial bottom gillnets, light and heavy, were used to give a

122 gradient of commercial conditions. All nets were commercial plaice gillnets, and heavy and light

123 nets differed only in the specifications of the head- and leadlines (Table 1). The headline was

124 different for the two gear types as it influences the inclination of the net and has commonly more

125 buoyancy for heavier nets in commercial conditions. It is commercial practice to work with such

126 a net height when targeting plaice $(1.1 \mathrm{~m})$. Mesh size was selected according to the fish target at

127 the chosen trial location, i.e., plaice on sandy habitat. Both net types were made by Daconet

128 (www.daconet.dk) with the same manufacturing process.

129 Pilot experiment: stereo recording units and their calibration 
130 Each observation unit was composed of a simple metallic frame made of $1 \mathrm{~cm}$ diameter steel 131 sticks (Fig. 1). Each metallic frame was ballasted with concrete poured in $7.5 \mathrm{~cm}$ diameter and $13212.5 \mathrm{~cm}$ long polyvinyl chloride (PVC) tubes at each foot. The use of a light frame ensured a 133 surface as small as possible for limiting drag, whereas the heavy feet guaranteed that the frame 134 would remain in position when lowered on the seabed. Two cameras in their waterproof housing 135 were mounted on the frame at a distance of $65 \mathrm{~cm}$ from each other and protected by netting (Fig.

136 1). The use of netting aimed at preventing entanglement of the netting of the gillnet into the 137 frame when in contact. Cameras were GoPro Hero 3 and 3+ cameras, each pair of a recording 138 unit having identical settings (type of camera and video mode). For all fleets, the video 139 resolution was set to 1080p SuperView, i.e., the sides of the video were stretched out for greater 140 viewing, the frame per second was set to 30 , and the field of view was set to Ultra Wide. Initial 141 testing of the set-up with resolution set to $4 \mathrm{~K}$ and frame per second set to 12 resulted in 142 measurement errors exceeding $25 \%$.

143 A 3D calibration frame of $80 \times 51 \times 31 \mathrm{~cm}$ with a 9-by-15 node pattern in the front face and 144 an 8-by-5 node pattern in the back face was used (Fig. 2). The front face was made of perspex 145 acrylic glass (PMMA) (http://vink.dk/), which can refract light when looking at the back frame 146 and slightly change the apparent position of the nodes (Neuswanger et al., 2016). A correction 147 was applied to compensate for light refraction by the front frame based on the thickness of the 148 material (35mm), the refractive index of the material (PMMA, 1.491), and the refractive index 149 of the medium (salt water, 1.342) (Neuswanger et al., 2016).

150 Each observation unit, consisting of two cameras mounted on a metallic frame was submerged 151 in water and calibrated at the Nordsøen Oceanarium (http://nordsoenoceanarium.dk/). 


\section{Pilot experiment: experimental set-up and measurement of water flow speed}

153 Three individual net panels were attached at the floatlines to form a fleet, similar to

154 commercial practice (Fig. 3a). All fleets were set in a straight line parallel to the coast and the

155 predominant current direction. Fleets were anchored at both ends with four kg anchors using six

156 metres bridle lines following commercial practices. As the motion at a specific section of the net

157 depends on its relative position (Shimizu et al., 2004), each stereo recording unit was positioned

158 on the seabed facing the middle length of the fleet, i.e., the part of the net the most likely to slide

159 assuming that the nets are set in a straight line, at about 1 to $2 \mathrm{~m}$ from the net (Fig. 3b). Three

160 fleets were soaked at the same time for two to three hours during the day. Fleets soaked together

161 formed a run. Data was collected while the gear was fully deployed on the seabed.

162 Nets were marked with different red tape patterns on the leadline to ensure that these marks

163 would easily be uniquely identified on the video recordings (Fig. 3 and 4). A high resolution

164 clock (B. Lundgren, pers. comm.) was recorded at the beginning of every recording, providing a

165 distinctive feature to synchronize the video recordings from the left and right cameras to the

166 nearest video frame.

167 The water speed was recorded using two sets of a GPS device (GP-102,

168 www.canmore.com.tw) attached to a buoy and left drifting during data collection (Fig. 5). A

169 holed PVC tube with attached lead hanging from the buoy was used to make sure that the

170 measurement gave the current speed in the water column and not at the surface (wind drift). Use

171 of the flow speed average from the bottom up to the net height could lead to more precise

172 calculation by incorporating vertical difference in flow speed caused by the bottom boundary

173 layer, but it is commonly accepted to use the current speed measured at the median net height in 
174 the mid-point location between the nets (Matuda and Sannomiya, 1977a, b; Matuda and

175 Sannomiya, 1978; Matuda, 1988; Shimizu et al., 2007).

176 Hourly instantaneous horizontal seawater velocities (2D) at $1 \mathrm{~m}$ depth were also extracted

177 from the Forecasting Ocean Assimilation Model $7 \mathrm{~km}$ Atlantic Margin model (FOAM AMM7)

178 (EU Copernicus, 2017). The $7 \mathrm{~km}$ resolution of the model restricts its utility in the coastal zone

179 where strong sub-grid scale variability in shallow water bathymetry affects the wave field, and

180 modelled data was therefore used as an overall indication of water flow speed in the area, but

181 not for instantaneous measurement at each net position.

182 Pilot experiment: data analysis

183 The position of the calibration frame defined the $3 \mathrm{D}$ coordinate system, i.e., the origin $(0,0$,

184 0) was the bottom left point on the front face of the calibration frame, the front and back faces

185 were found in the $x-z$ plane, with the front face in the plane $y=0$ and the back face in the plane

$186 y=$ distance between both faces (Fig. 2). Thus, the net movements in the X dimension were

187 positive when the net moved rightward or negative leftward (Fig. 4). The movements in the Y

188 dimension were positive when the net moved backward or negative forward. As the observation

189 units were facing the coast during deployment, the movements in the $\mathrm{Y}$ dimension were positive

190 when the net moved towards the coast and negative towards the open sea. The movements in the

$191 \mathrm{X}$ and $\mathrm{Y}$ dimensions represent the sweeping motion of the net. The movements in the $\mathrm{Z}$

192 dimension were positive when the net moved upward, i.e., lifting off the seabed, or negative

193 downward, i.e., dropping on the seabed. The movements in the $\mathrm{Z}$ dimension represent the seabed 194 penetration.

195 We checked for data entry mistakes or calibration problems by examining diagnostic error 196 measures provided for each 3D point by Vidsync (Neuswanger et al., 2016). To quantify actual 
197 errors in 3D measurements, the calculated (VidSync) and measured (measuring tape) distances

198 between two nodes as well as between the two faces of the calibration frame were compared in a

199 first control test, and the calculated and measured distances between two coloured threads on the

200 leadline of both light and heavy gillnets were compared in a second control test. The first point

201 calculated was set as a reference starting point with a given position of zero in the three

202 dimensions, and the position value of this reference point was subtracted from the position

203 values of the following points. The dynamic behavior of the leadline was analysed using a

204 simple motion metrics in the three spatial dimensions, i.e., the maximum distance covered by the

205 leadline in each dimension, calculated as the difference between the maximum and the minimum

206 position values of each mark.

207 Significant differences between light and heavy net configurations were tested for as follows.

208 Data exploration was applied following Zuur et al. (2010). The effect of net configuration (light

209 or heavy), run (I or II) and dimension (X, Y or Z) on the maximum movement of the leadline

210 was initially modelled as a linear regression model containing sensible interactions based on

211 experimental knowledge and data exploration as in model (1). A log-transformation was applied

212 on the response variable as a solution to heterogeneity of variance. As the video recording

213 duration varied between marks (Table 2), duration was used as an offset. The linear regression

214 model is given by:

$215 \log \left(\mathrm{Y}_{i}\right)=\beta\left(\right.$ Dimension $\left._{i}, \mathrm{Net}_{i}, \operatorname{Run}_{i}\right)+1 * \log \left(\right.$ Duration $\left._{i}\right)+\varepsilon_{i}$ with $\varepsilon_{i} \sim N\left(0, \sigma_{i}{ }^{2}\right)$

216 where $\mathrm{Y}_{i}$ is the maximum movement of the $i$ th mark, $\beta$ is the population slope and $\varepsilon_{i}$ is the

217 residual normally distributed with expectation 0 and variance $\sigma_{i}^{2}$. 
218 Model selection was applied to model (0) by dropping individual explanatory variables one by

219 one based on hypothesis testing (F-statistic), and resulted in the preferred model (2):

$220 \log \left(\mathrm{Y}_{i}\right)=\beta\left(\right.$ Dimension $\left._{i}\right)+\gamma\left(\operatorname{Net}_{i}, \operatorname{Run}_{i}\right)+1 * \log \left(\right.$ Duration $\left._{i}\right)+\varepsilon_{i}$ with $\varepsilon_{i} \sim N\left(0, \sigma_{i}^{2}\right)$

221 All parameters were tested significant at $p$-value $<0.001$. The four assumptions that allow the

222 sample data to be used to estimate the population data are: normality, homogeneity,

223 independence and fixed explanatory variable (i.e., measurement error in the explanatory variable

224 is small compared to the noise in the response variable). The chosen model (2) was validated by

225 visual inspection of the residuals.

226 The video recordings were processed with VidSync version 1.66 (www.vidsync.org). All

227 other analyses were performed by the open-source software R 3.2.3 (R Core Team, 2016).

\section{3. Results}

\section{Data collected and error measures}

230 Video recordings from five fleets were clear and long enough for analysis, i.e., three fleets for

231 run I and two fleets for run II (Table 2). Nets were deployed at 3 and 1.5-2 $\mathrm{m}$ depth,

232 respectively, for runs I and II. All video recordings were collected in good weather and sea

233 conditions. Modelled hourly water velocities were (average \pm standard deviation) $0.049 \pm 0.003$

234 and $0.031 \pm 0.027 \mathrm{~m} . \mathrm{s}-1$, respectively, for runs I and run II, which was in agreement with

235 measured water velocities of $0.028 \pm 0.025$ m.s- 1 for run II. A total of eight marks could be

236 uniquely identified on the leadline, i.e., one mark for fleet $\mathrm{Ia}$, Ib, IIa, two marks for fleet Ic and

237 three marks for fleet IIb (Table 2). Total video recordings duration per mark ranged from 13 to

238138 minutes, with an average of (mean \pm standard deviation) $73 \pm 84$ min for light nets and 109 
$239 \pm 41 \mathrm{~min}$ for heavy nets (Table 2). An extract of one of the recordings is given as an example

240 (supplementary material).

241 Diagnostic error measures provided for each 3D point by Vidsync did not show any data

242 entry mistake or calibration problem.

243 Distortion corrections reduced the distortion error, i.e., the distance between the input screen

244 points and the reprojected screen points, by (mean \pm standard deviation) $54 \pm 12 \%$ for all cameras

245 in all recording units. The remaining distortion per point was $0.94 \pm 0.21$ pixels on average for

246 all cameras in all recording units. There was a slight increase in absolute error for calculations

247 near the edge or centre of the screen for some of the video recordings.

248 In the first control test, the calculated (Vidsync) and measured (measuring tape) distances

249 between two nodes as well as between the two faces of the calibration frame were compared.

250 The Vidsync calculated distances were quite close to the measurements of the real distances,

251 with on average all measurement errors smaller than $10 \%$ (Fig. 6a).

252 In a second control test, the calculated (Vidsync) and measured (measuring tape) distances

253 between two coloured threads on the leadline of three light and four heavy gillnets were

254 compared. The Vidsync calculated distances were quite close to the measurements of the real

255 distances, with on average all measurement errors smaller than $25 \%$ (Fig. 6b). However, overall,

256 measurement errors for heavy nets in run I were up to around 150\%, underestimating the

257 calculated distances compared to the measured ones.

258 Based on in-situ stereo vision measurements, the presented methodology can quantify the 259 dynamic behavior of the leadline of commercial bottom gillnets gillnet. 


\section{Dynamic behaviour of the leadline and maximum distance covered by the leadline}

261 Marks were either stationary, e.g., mark 1 in the Y dimension, moved regularly continuous,

262 e.g., mark 1 in the $\mathrm{X}$ dimension, or moved with a sudden step, e.g., mark 6 in the $\mathrm{X}$ and $\mathrm{Y}$

263 dimension (Fig. 7). Overall, marks on the same net moved similarly, e.g., marks 3 to 5 on fleet

264 Ic, even though local disparities were found, e.g., marks 7 and 8 on fleet IIb (Fig. 7). When

265 moving, all marks moved in a single direction in all dimensions, e.g., to the right only for mark

2661 or to the left only for mark 6 (Fig. 7). However, not all fleets moved in the same direction, e.g.,

267 not all moved leftwards or towards the coast (Fig. 7).

268 The leadline was moving but not penetrating into the seabed as seen from the recorded

269 images, downward movements as calculated values in the $\mathrm{Z}$ dimension being most likely due to

270 slight disparities in the seabed features. The leadline was apparent in most of the footages,

271 except in rare occasions in which about five $\mathrm{cm}$ in length were not visible. The sea bottom was

272 slightly bumpy and it was not possible to see if the leadline was covered by sand or only behind

273 a bump in these few occasions.

274 The maximum distance covered by each mark on the leadline ranged from 0.14 to $1.10 \mathrm{~m}$, 2750.06 to $2.01 \mathrm{~m}$ and 0.02 to $0.26 \mathrm{~m}$ in the $\mathrm{X}, \mathrm{Y}$ and $\mathrm{Z}$ dimensions, respectively, with an average of 276 (mean \pm standard deviation) $0.96( \pm 0.20)$ for light and $0.31( \pm 0.15) \mathrm{m}$ for heavy nets, $1.5( \pm 0.67)$

277 for light and $0.38( \pm 0.25) \mathrm{m}$ for heavy nets, and $0.14( \pm 0.17)$ for light and $0.06( \pm 0.03) \mathrm{m}$ for

278 heavy nets, in the $\mathrm{X}, \mathrm{Y}$ and $\mathrm{Z}$ dimensions, respectively (Table 2). The maximum swept area

279 covered by the movements of each observed mark ( $\mathrm{X}$ and $\mathrm{Y}$ dimensions) ranged from 0.02 to

$2801.65 \mathrm{~m} 2$, with an average of $1.41( \pm 0.34)$ and $0.13( \pm 0.15) \mathrm{m} 2$ for light and heavy nets,

281 respectively (Table 2). The leadline movements in the three dimensions were found to be

282 significantly different, with larger maximum movements in the $\mathrm{Y}$ dimension (Table 3). 
283 Whatever the net type, the leadline moved $1.14(0.49-2.65)$ times more in the $\mathrm{Y}$ dimension

284 (backward-forward) than in the X dimension (rightward-leftward), and 7.30 (3.15-16.89) times

285 more in the $\mathrm{Y}$ than in the $\mathrm{Z}$ dimension (upward-downward) (Fig. 8).

\section{Differences between net types and runs}

287 The leadline movements were significantly different for the two tested net configurations: for 288 both runs, light nets were moving more than heavy nets (Table 3). Whatever the dimension, light 289 nets moved 32.53 (95\% confidence limits: 11.01-96.09) times more than heavy nets in run I, and 2901.41 (0.43-4.61) in run II (Fig. 8). A significant interacting effect of runs (Table 3) was found, 291 with both light and heavy nets moving more in run I than run II. Light nets moved 26.79 (6.81-

292 105.47) times more in run I than in run II, and heavy nets moved $1.16(0.50-2.68)$ times more in 293 run I than in run II. This is in line with higher water velocities in run I compared to run II.

\section{4. Discussion}

\section{Stereo-imaging for quantifying gear dynamic behavior in-situ}

296 The dynamic behavior of the leadline of commercial bottom gillnets could be quantified in 297 details using the presented methodology based on measurements of in-situ stereo vision 298 recordings. The methodology quantify both the seabed penetration and sweeping motion of the 299 leadline. This methodology can be further applied to assess habitat effect of other gear types, 300 especially other static gears such as creels and pots, or more generally further assess gear 301 dynamic behavior in-situ. Indeed, as net geometry affects the gear selectivity, an improved 302 understanding of the gear dynamic behavior would provide a better insight into the capture 303 process (Shimizu et al., 2004; Herrmann et al., 2009). 
The stereo-imaging experimental set-up, i.e., the choice of camera separation and the

305 dimensions and position of the calibration frame, was configured to measure relatively small

306 objects close to the cameras. Accuracy and precision decreased as distance from the cameras

307 increased. The nets were not expected to move in such an order of magnitude, but a larger

308 chessboard, i.e., large enough to fill the screen, could have helped limit our measurement errors.

309 The fish eye effect could be reduced by limiting the field of view (instead of choosing ultra wide

310 setting).

311 A variety of challenges were faced when deploying the observation units near the nets at sea,

312 among which water turbidity, also noticed as a limitation for optical methods by Lucchetti and

313 Sala (2012) and Struthers et al. (2015). The video recordings could also appear blurry due to the

314 scattering effects of particles in the water column, and images could be exposed differently from

315 the two cameras due to irregular lightning and displacement between the cameras (Schmidt and

316 Rzhanov, 2012). These optical limitations reduced the number of recorded images that could be

317 processed. A camera that only captures light reflected from objects further away than a certain

318 distance could be used to remove the effects of scattered light and therefore solve the issue of

319 water turbidity (under development, L.A. Krag, pers. comm.).

320 Calibration and distortion corrections obtained in a tank were used for processing the in-situ

321 video recordings. The same camera specifications, i.e., camera settings and relative orientation,

322 for each recording unit, were used but any optical adjustment such as removing a camera from

323 its underwater housing to change a battery or a change of the angle between the cameras during

324 transportation/aboard the vessel may have affected the parameters and therefore the results. The

325 control tests did not show major issues, and one can therefore rely on the order of magnitude of 
326 the results. But, the cameras should remain fixed throughout the experiment in a later use of the

327 stereo-imaging method.

\section{Pilot estimation of gillnets 3D dynamic behaviour and their seabed effects}

329 The leadline of bottom gillnets, fully deployed on the bottom, could sweep the seabed in

330 sandy habitats up to about $2 \mathrm{~m}$, for the most part in the order of magnitude of $10 \mathrm{~cm}$.

331 Movements were either continuous or in a sudden step, which was different from the periodical

332 displacement observed by Shimizu et al. (2004). This could be due to a different initial net shape

333 and spread of the leadline for each fleet when reaching the sea bottom (Shimizu et al., 2007), or

334 local water flow disparities. The in-situ measurements of the leadline showed that movements

335 were the smallest in the $\mathrm{Z}$ dimension, less than a few centimeters. The leadline was moving but

336 not penetrating into the seabed as seen from the recorded images, downward movements as

337 calculated values in the $\mathrm{Z}$ dimension being most likely due to slight disparities in the seabed 338 features.

339 In terms of seabed disturbance, this means that the physical disruption of the seabed

340 (penetration) of gillnets is minimal compared to the sweeping of the gear, whereas seabed

341 penetration was observed as partly responsible for habitat physical impact in active fishing gears

342 (Eigaard et al., 2016; Depestele et al., 2016). The potential direct damage to the benthos would

343 therefore originate from the sweeping movements of the gillnets, as the leadline and netting can

344 snag and entangle available entities. The sweeping movements of plaice gillnets in the Danish

345 fishery were found to be higher than usually estimated by experts, but cannot be compared to

346 other in-situ measurements as these are the first quantitative measurements to our knowledge. A

347 maximum of $30 \mathrm{kms}$ of nets are soaked in a typical bottom-set gillnets fishing operation

348 (Montgomerie, 2015). The swept area can roughly be estimated to about $0.04 \mathrm{~km}^{2}$ for light nets 
and $0.01 \mathrm{~km}^{2}$ for heavy nets (based on a rectangle area calculation using the average measured

350 range per mark in the $\mathrm{Y}$ dimension as presented above, i.e., 1.5 for light and $0.38 \mathrm{~m}$ for heavy

351 nets). This is lower than any of the hourly swept area estimated for active fishing gears by

352 Eigaard et al. (2016), ranging from $0.05 \mathrm{~km}^{2}$ for beam trawl to $1.5 \mathrm{~km}^{2}$ for Scottish seining

353 surface impact. However, the swept area of an active gear is swept once by the gear, whereas

354 passive gear are likely to sweep the same area multiple times. The measured movements were

355 representative only to a certain point of what really happens: as the nets were getting too far

356 from or too close to the recording unit, it was not possible to take measurements anymore. The

357 present measurements of the movement of the leadline are therefore underestimated. However,

358 the movement of the leadline was not unlimited as the fleets were anchored on the bottom. For

359 the same reason, a major difference between longer soak durations on the estimated swept area

360 was not expected.

361 The dynamic behavior of the leadline was analysed using a simple motion metrics in the three

362 spatial dimensions, i.e., the maximum distance covered by the leadline in each dimension.

363 However, how fast the leadline moves is also expected to play a key role in the assessment of

364 the potential effects of the leadline movement on the seabed. Indeed, the fastest movements of

365 the leadline are the ones most likely to cause damage. As observed previously, marks moved

366 either regularly continuous, or with a sudden step, and speed was therefore not a good indicator.

367 Further assessment should include a spatio-temporal trajectory analysis, with focus on

368 acceleration, i.e, change in velocity with time.

369 The observations of the pilot project only covered the soaking phase of a gillnetting operation,

370 i.e., when the gear was fully deployed on the bottom, and not the retrieval of the gear, therefore

371 not covering the total potential habitat effect of bottom gillnets. Shester and Micheli (2011) 
372 observed the entanglement and removal of kelp plants and gorgonian corals by set gillnets while

373 being hauled. Effects of hauling are more likely to be destructive as more power is exerted

374 through the nets (hauler) than when soaking, for which, e.g., a stone could eventually stop the

375 net. It is however known from fishermen practices that the way the gear is handled when hauling

376 can significantly reduce possible habitat damage, e.g., hauling in the current direction.

\section{Gear configuration as mitigation measure}

378 As demonstrated in this experiment, the gear configuration affects the sweeping of the nets,

379 with light nets moving significantly more than heavy ones. Whereas the general perception is

380 that heavy gears are more destructive to the habitat, such as in active gears (Kaiser et al., 2002),

381 it was demonstrated here that a heavier leadline would result in less movement, being the actual

382 issue in terms of potential habitat damage of bottom-set gillnets. Therefore, gear configuration

383 has a strong mitigation effect regarding the sweeping behavior of the leadline, and habitat

384 damage could be reduced by using nets mounted with heavier leadlines.

385 In addition to the tested net configuration, i.e., light and heavy nets, other components of the 386 fishing gear in gillnets could be looked at to mitigate their habitat effects. Bridles attached to the 387 head or bottom line will give the netting different types of curves which will affect the drag 388 (Stewart and Ferro, 1985). Twine diameter, mesh size, netting hanging ratio and length of fleets, 389 as well as the way the nets are set out could also affect the drag and therefore the leadline 390 movement of bottom-set gillnets.

\section{General applicability of the results}

392 Due to the limited number of observations and choice of model, movement values presented 393 here were not meant to be predicted outside of the experimental conditions. Water flow speeds 394 during data collection were lower than the average range in coastal Danish waters (0.26 to 

conditions of mild sea conditions gave conservative estimates. The flow from waves, induced by

397 wind, and current, induced by both tides and wind, represents the most common flow condition 398 on the seabed for shallow water depths at our scales of interest (spatial and temporal) (Jensen 399 and Jónsson, 1987; Otto et al., 1990; Myrhaug, 1995; Soulsby, 1997). The complex effects of 400 water flow, waves and wind, can change at a small scale, and influence the behavior of the gear 401 (Shimizu et al., 2004). These local differences in water flow could be a reason for the significant 402 interacting effect of runs. When moving, all marks moved in a single direction in all dimensions, 403 which indicated that movements were not caused by the local action of waves, i.e., flow and 404 surge which would have resulted in, e.g., repeated forward-backward movements. When 405 moving, not all fleets moved in the same direction, which indicated that movements were not 406 caused by the overall action of waves, i.e., towards the coast. Detailed measurement of the 407 current direction and speed in further experiments could provide with a better understanding of 408 the environmental variables at stake. Very shallow waters were needed to test how to operate the 409 camera cages, and also because water was turbid at the time of data collection. Further 410 estimations should be run in deeper waters for which water flow conditions would be different, 411 as the turbulent boundary layer does not occupy the entire water column contrary to shallow 412 waters (Soulsby, 1997; Otto et al., 1990). This is conditioned on an improved method that 413 allows to place an observation unit quite close to the net at such depths, e.g., using a sonar, and 414 external lightning to compensate for the reduced light conditions.

415 Because the pilot project was located in very shallow waters, a small net height was chosen. It is 416 commercial practice to work with such a net height, but higher nets may have an influence on 
417 the overall gear equilibrium and drag. So may caught fish, but it is generally assumed that fish

418 would not have a great effect (Shimizu et al., 2007).

\section{Supplementary material}

420 An extract of one of the video recordings is given as supplementary material at ICESJMS

421 online.

\section{Acknowledgements}

423 The authors wish to thank Bo Lundgren, Reinhardt Jensen, Søren Larsen Grønby and Aage

424 Thaarup from DTU Aqua, for their help with the calibration and experiment at sea. The authors

425 also wish to thank Martin Riis from the Nordsøen Oceanarium for use of the tank and Jason

426 Neuswanger for help with Vidsync. Finn Larsen (DTU Aqua) made valuable comments on the

427 manuscript and Anders Nielsen (DTU Aqua) assisted in the statistical analysis of the data. The

428 Ministry of Environment and Food of Denmark funded the present study as part of the

429 'Skånfisk' project, but was not involved in the conduct of the research or preparation of the

430 article.

$431 \quad$ References

432 Depestele, J., Ivanović, A., Degrendele, K., Esmaeili, M., Polet, H., Roche, M., Summerbell, K., 433 Teal, L.R., Vanelslander, B., O’Neill, F.G. 2016. Measuring and assessing the physical 434 impact of beam trawling. ICES Journal of Marine Science, 73: i15-i26.

435 E.C. 2008. Directive 2008/56/EC of the European Parliament and of the Council of 17 June 4362008 establishing a framework for community action in the field of marine environmental 437 policy (Marine Strategy Framework Directive). 
E.C. 2016. Community Fishing Fleet Register Data Base. Available from

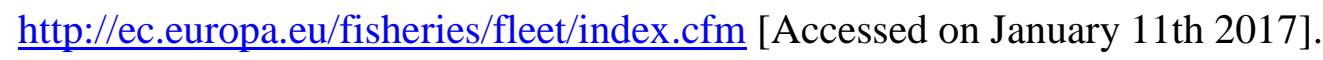

440 Eigaard, O.R., Bastardie, F., Breen, M., Dinesen, G.E., Hintzen, N.T., Laffargue P., Mortensen, 441 L.O., Nielsen, J.R., Nilsson, H.C., O’Neill, F.G., Polet, H., Reid, D.G., Sala, A., Sköld, M., 442 Smith, C., Sorensen, T.K., Tully, O., Zengin, M., Rijnsdorp, A.D. 2016. Estimating seabed 443 pressure from demersal trawls, seines, and dredges based on gear design and dimensions. $444 \quad$ ICES Journal of Marine Science, 73: i27-i43.

445 Eno, N.C., Frid, C.L.J., Hall, K., Ramsay, K., Sharp, R.A.M., Brazier, D.P., Hearn, S., Dernie, 446 K.M., Robinson, K.A., Paramor, O.A.L., Robinson, L.A. 2013. Assessing the sensitivity of 447 habitats to fishing: from seabed maps to sensitivity maps. Journal of Fish Biology, 83: 826$448 \quad 846$.

449 EU Copernicus, 2017. Atlantic - European North West Shelf - Ocean Physics Analysis and 450 Forecast (NORTHWESTSHELF_ANALYSIS_FORECAST_PHYS_004_001_b). Available 451 from EU Copernicus Marine Service Information http://marine.copernicus.eu/services452 portfolio/access-to-

453 products/?option=com_csw\&view=details\&product_id=NORTHWESTSHELF_ANALYSIS $454 \quad$ FORECAST_PHYS 004_001_b [Accessed June $9^{\text {th }}$ 2017]

455 Grabowski, J.H., Bachman, M., Demarest, C., Eayrs, S., Harris, B.P., Malkoski, V., Packer, D., 456 Stevenson, D. 2014. Assessing the vulnerability of marine benthos to fishing gear impacts. 457 Reviews in Fisheries Science, 22: 142-155. 
He and Pol, 2010. Fish behavior near gillnets: capture processes and influencing factors. Behavior of Marine Fishes: Capture Processes and Conservation Challenges, WileyBlackwell, pp. 183-203.

Hermsen, J.M., Collie, J.S., Valentine, P.C. 2003. Mobile fishing gear reduces benthic megafaunal production on Georges Bank. Marine Ecology Progress Series, 260: 97-108.

Herrmann, B., Krag, L.A., Frandsen, Madsen, N., Lundgren, B., Stæhr, K.-J., 2009. Prediction of selectivity from morphological conditions: methodology and a case study on cod (Gadus morhua). Fish. Res., 97, 59-71.

Humborstad, O.-B., Nøttestad, L., Løkkeborg, S., Rapp, H. T. 2004. Rox-Ann bottom classification system, sidescan sonar and video-sledge: spatial resolution and their use in assessing trawling impacts. ICES Journal of Marine Science, 61: 53-63.

Jennings, S., Kaiser, M.J. 1998. The effects of fishing on marine ecosystems. Advances in Marine Biology, 34: 201-212, 212e, 213-352.

Jensen, T.G., Jónsson, S. 1987. Measurement and analysis of currents along the Danish west coast. Deutsche Hydrografische Zeitschrift, 40: 193-213.

Kaiser, M.J., 1998. Significance of bottom-fishing disturbance. Conservation Biology, 12: $1230-1235$.

Kaiser, M.J., Spence, F.E., Hart, P.J.B., 2000. Fishing-gear restrictions and conservation of benthic habitat complexity. Conservation Biology, 14: 1512-1525.

Kaiser, M.J., Collie, J.S., Hall, S.J., Jennings, S., Poiner, I.R. 2002. Modification of marine habitats by trawling activities: prognosis and solutions. Fish and Fisheries, 3: 114-136. 
Lucchetti, A., Sala, A. 2012. Impact and performance of Mediterranean fishing gear by sidescan sonar technology. Canadian Journal of Fisheries and Aquatic Sciences, 69: 1806-1816.

Matuda, K. 1988. Headline height of bottom gill nets set across a water flow. Fisheries Research, 6: 167-179.

Matuda, K. Sannomiya 1977a. Theory and design of bottom drift net. 2. Results of numerical analysis on motion of gear. Bulletin of the Japanese Society of Scientific Fisheries, 43: 679687.

Matuda, K. Sannomiya, N. 1977b. Theory and design of bottom drift net. 1. Method of numerical analysis on motion of gear. Bulletin of the Japanese Society of Scientific Fisheries, 43: 669-678.

Matuda, K. Sannomiya, N. 1978. Theory and design of bottom drift net. 3. Analytical solutions of equation of motion of gear. Bulletin of the Japanese Society of Scientific Fisheries, 44: 713.

Montgomerie, M., 2015. Basic fishing methods. Ed. by R. Forbes. Seafish, Edinburgh. 104 pp.

Myrhaug, D. 1995. Bottom friction beneath random waves. Coastal Engineering, 24: 259-273.

National Geospatial-Intelligence Agency of the United States Government, 2013. Sailing directions for Skagerrak and Kattegat. 14th ed., 168p.

Neuswanger, J., Wipfli, M.S., Rosenberg, A.E., Hughes, N.F. 2016. Measuring fish and their physical habitats: versatile $2 \mathrm{D}$ and 3D video techniques with user-friendly software. Canadian Journal of Fisheries and Aquatic Sciences, 73: 1861-1873. 
499 Olson, J., Clay, P.M., da Silva, P.P. 2014. Putting the seafood in sustainable food systems.

$500 \quad$ Marine Policy, 43: 104-111.

501 O’Neill, F.G., Summerbell, K., Breen, M. 2009. An underwater laser stripe seabed profiler to

502 measure the physical impact of towed gear components on the seabed. Fisheries Research,

503 99: 234-238.

504 Otto, L., Zimmerman, J.T.F., Furnes, G.K., Mork, M., Saetre, R., Becker, G. 1990. Review of

505 the physical oceanography of the North Sea. Netherlands Journal of Sea Research, 26: 161-

506238.

507 R Core Team. 2016. R: A language and environment for statistical computing. R Foundation for 508 Statistical Computing, Vienna, Austria.

509 Schmidt, V.E., Rzhanov, Y. 2012. Measurement of micro-bathymetry with a GOPRO

510 underwater stereo camera pair. 2012 Oceans, IEEE, pp. 6404786.

511 Shester, G., and Micheli, F. 2011. Conservation challenges for small-scale fisheries: bycatch and 512 habitat impacts of traps and gillnets. Biological Conservation, 144: 1673-1681.

513 Shimizu, T., Takagi, T., Suzuki, K., Hiraishi, T., Yamamoto, K. 2004. Refined calculation

514 model for NaLA, a fishing net shape simulator, applicable to gill nets. Fisheries Science, 70 :

$515 \quad 401-411$.

516 Shimizu, T., Takagi, T., Korte, H., Hiraishi, T., Yamamoto, K. 2007. Application of NaLA, a

517 fishing net configuration and loading analysis system, to bottom gill nets. Fisheries Science, $518 \quad 73: 489-499$. 
519 Smith, C.J., Rumohr, H., Karakassis, I., Papadopoulou, K.-N. 2003. Analysing the impact of

520 bottom trawls on sedimentary seabeds with sediment profile imagery. Journal of Expermental

$521 \quad$ Marine Biology and Ecology, 285-286: 479-496.

522 Soulsby, R. 1997. Dynamics of marine sands: A manual for practical applications. London:

523 Telford, 249p.

524 Stewart, P.A.M. 1988. Measurements of the effects of tidal flow on the headline heights of 525 bottom-set gillnets. Fisheries Research, 6: 181-189.

526 Stewart, P.A.M., Ferro, R.S.T. 1985. Measurements on gill nets in a flume tank. Fisheries

$527 \quad$ Research, 3: 29-46.

528 Struthers, D.P., Danylchuk, A.J., Wilson, A.D.M., Cooke, S.J. 2015. Action cameras: bringing $529 \quad$ aquatic and fisheries research into view. Fisheries, 40: 502-512.

530 Suuronen, P., Chopin, F., Glass, C., Løkkeborg, S., Matsushita, Y., Queirolo, D., Rihan, D.

531 2012. Low impact and fuel efficient fishing - Looking beyond the horizon. Fisheries

532 Research, 119-120: 135-146.

533 Takagi, T., Shimizu, T., Korte, H. 2007. Evaluating the impact of gillnet ghost fishing using a 534 computational analysis of the geometry of fishing gear. ICES Journal of Marine Science, 64: $535 \quad 1517-1524$.

536 Uhlmann, S.S., and Broadhurst, M.K. 2013. Mitigating unaccounted fishing mortality from 537 gillnets and traps. Fish and Fisheries, 16: 183-229.

538 Watson, R., Revenga, C., Kura, Y. 2006. Fishing gear associated with global marine catches. I. 539 Database development. Fisheries Research, 79: 97-102. 
540 Zuur, A.F., Ieno, E.N., Elphick, C.S. 2010. A protocol for data exploration to avoid common 541 statistical problems. Methods in Ecology and Evolution, 1: 3-14. 
Table 1. Specifications of individual net panels used in the experimental set-up for light and heavy gear types. Height is given as stretched height. Headline and leadline types are given as specified by the net maker Daconet (firm's internal specification without unit). Specifications differing between the two gear types, light and heavy, are emphasized in bold.

\begin{tabular}{|c|c|c|c|}
\hline \multicolumn{2}{|c|}{ Gear specifications } & Light & Heavy \\
\hline \multirow[t]{2}{*}{ Net } & Type & \multicolumn{2}{|c|}{ Gillnet } \\
\hline & Target species & \multicolumn{2}{|c|}{ Plaice } \\
\hline \multirow[t]{4}{*}{ Twine } & Diameter & \multicolumn{2}{|c|}{$0.30 \mathrm{~mm}$} \\
\hline & Type & \multicolumn{2}{|c|}{ Monofil } \\
\hline & Material & \multicolumn{2}{|c|}{ Nylon } \\
\hline & Knot & \multicolumn{2}{|c|}{ Double } \\
\hline Mesh size & Nominal (bar length) & \multicolumn{2}{|c|}{$68 \mathrm{~mm}$} \\
\hline \multirow[t]{3}{*}{ Dimensions } & Height (mesh depth) & \multicolumn{2}{|c|}{$1.1 \mathrm{~m}(8.5)$} \\
\hline & Length (knot length) & \multicolumn{2}{|c|}{82 m (4800) } \\
\hline & Hanging ratio & \multicolumn{2}{|c|}{$25 \%$} \\
\hline \multirow[t]{2}{*}{ Headline } & Type (Hau Line mono) & 1.5 & 2.5 \\
\hline & Buoyancy per $100 \mathrm{~m}$ & $600 \mathrm{~g}$ & $1200 \mathrm{~g}$ \\
\hline \multirow[t]{2}{*}{ Leadline } & Type (Hau sinkline lead-free) & 1.5 & 3 \\
\hline & Weight per $100 \mathrm{~m}$ & $3.9 \mathrm{~kg}$ & 11 kg \\
\hline
\end{tabular}


Table 2. Run, fleet and net type for each of the eight marks on the leadline of gillnets observed in the pilot sea trial. Clip gives the total duration in min of the recorded images for each observed mark. The maximum distance (Max. distance) gives the maximum distance in m covered by the movements of each observed mark in the $\mathrm{X}, \mathrm{Y}$ and $\mathrm{Z}$ dimensions. The maximum swept area (Max. swept area) gives the maximum swept area in $\mathrm{m}^{2}$ covered by the movements of each observed mark in the $\mathrm{X}, \mathrm{Y}$ and $\mathrm{Z}$ dimensions.

\begin{tabular}{|c|c|c|c|c|c|c|c|c|}
\hline \multirow[t]{2}{*}{ Mark } & \multirow[t]{2}{*}{ Run } & \multicolumn{2}{|c|}{ Fleet Net type } & \multirow[t]{2}{*}{ Clip (min) } & \multicolumn{3}{|c|}{ Max. distance (m) } & \multirow[t]{2}{*}{ Max. swept area $\left(\mathrm{m}^{2}\right)$} \\
\hline & & & & & $\mathrm{X}$ & Y & Z & \\
\hline 1 & I & Ia & Heavy & 125 & 0.32 & 0.19 & 0.05 & 0.06 \\
\hline 2 & I & $\mathrm{Ib}$ & Light & 13 & 0.82 & 2.01 & 0.26 & 1.65 \\
\hline 3 & I & Ic & Heavy & 128 & 0.30 & 0.44 & 0.07 & 0.13 \\
\hline 4 & I & Ic & Heavy & 133 & 0.59 & 0.73 & 0.12 & 0.43 \\
\hline 5 & I & Ic & Heavy & 101 & 0.21 & 0.56 & 0.06 & 0.12 \\
\hline 6 & II & IIa & Light & 132 & 1.10 & 1.06 & 0.02 & 1.17 \\
\hline 7 & II & IIb & Heavy & 29 & 0.14 & 0.29 & 0.04 & 0.04 \\
\hline 8 & II & IIb & Heavy & 138 & 0.29 & 0.06 & 0.03 & 0.02 \\
\hline
\end{tabular}


Table 3. Estimates and standard errors (se) of the parameters in the chosen model for the log expected maximum movement of the leadline. All parameters were tested significant at p-value $<0.001$.

\begin{tabular}{|c|c|}
\hline Parameters & Estimate (se) \\
\hline \multicolumn{2}{|l|}{$\beta\left(\right.$ Dimension $\left._{i}\right)$} \\
\hline Dimension X & $-5.56(0.54)$ \\
\hline Dimension Y & $-5.43(0.54)$ \\
\hline Dimension Z & $-7.42(0.54)$ \\
\hline \multicolumn{2}{|l|}{$\gamma\left(\right.$ Net $_{i}$, Run $\left._{i}\right)$} \\
\hline Light net, Run I & $3.29(0.69)$ \\
\hline Light net, Run II & $0(0)$ \\
\hline Heavy net, Run I & $-0.19(0.54)$ \\
\hline Heavy net, Run II & $-0.34(0.59)$ \\
\hline
\end{tabular}




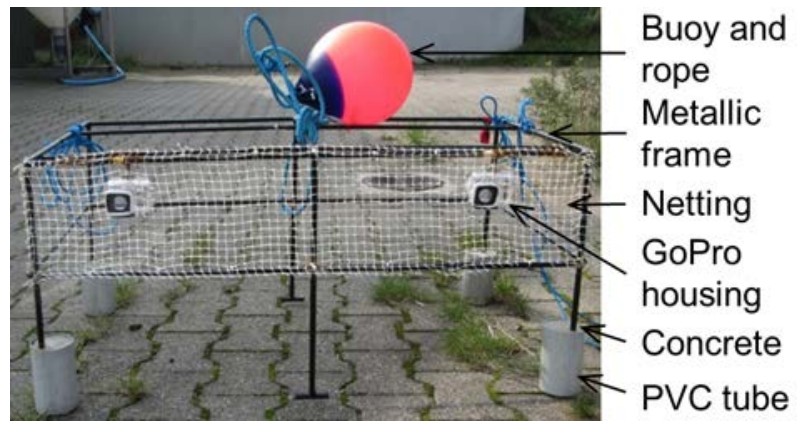

Fig. 1. The observation unit.

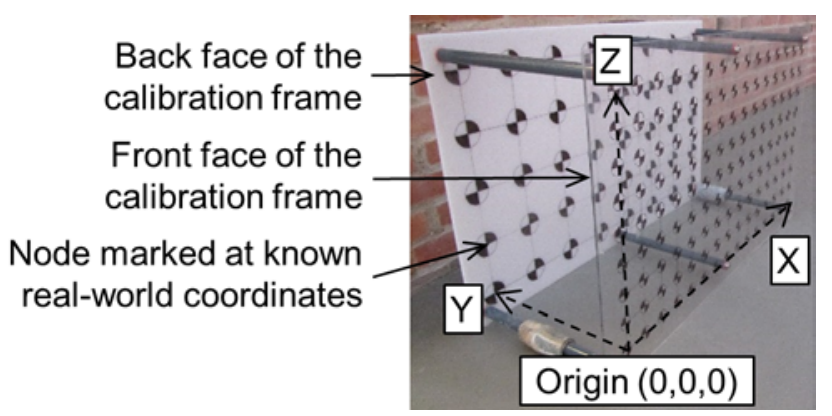

Fig. 2. The calibration frame.
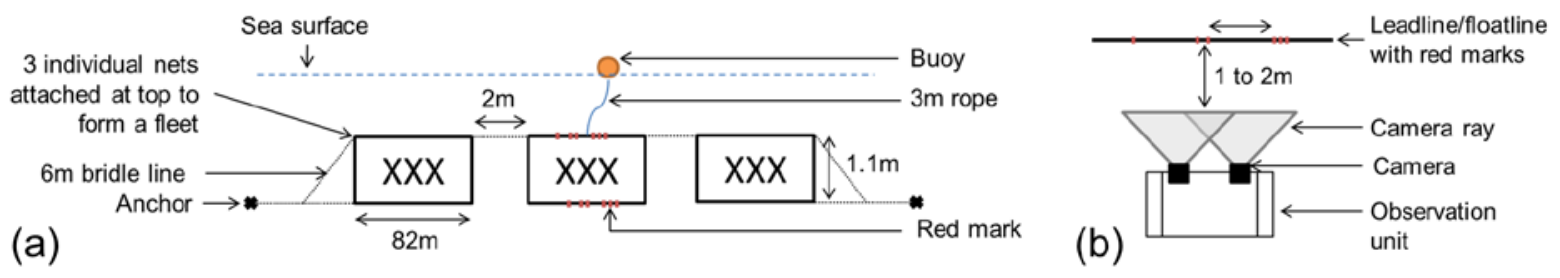

Fig. 3. Experimental set-up for stereo imaging with (a) side view of a fleet, i.e., a ganged sequence of 3 individual gillnets, set on the bottom, (b) top view of the observation unit positioned in front of a net. 


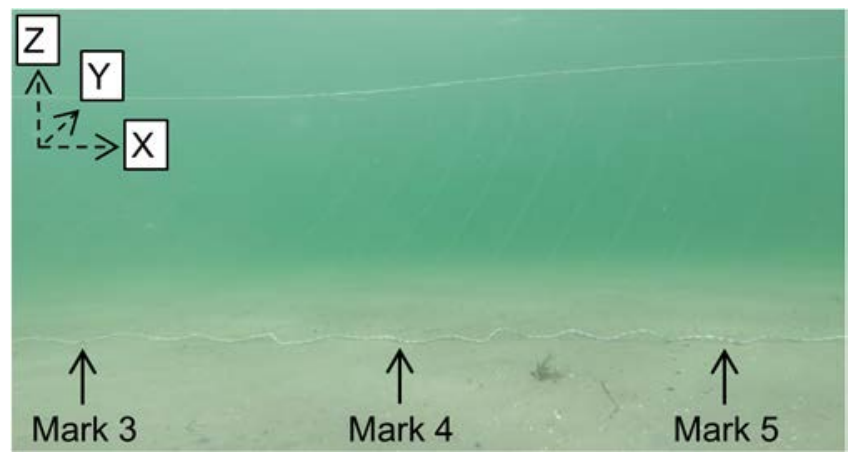

Fig. 4. An in situ example (fleet Ic) of the positions of three different marks (identified from 3 to 5) on the leadline of the same net recorded in the three dimensions (X, Y and Z).

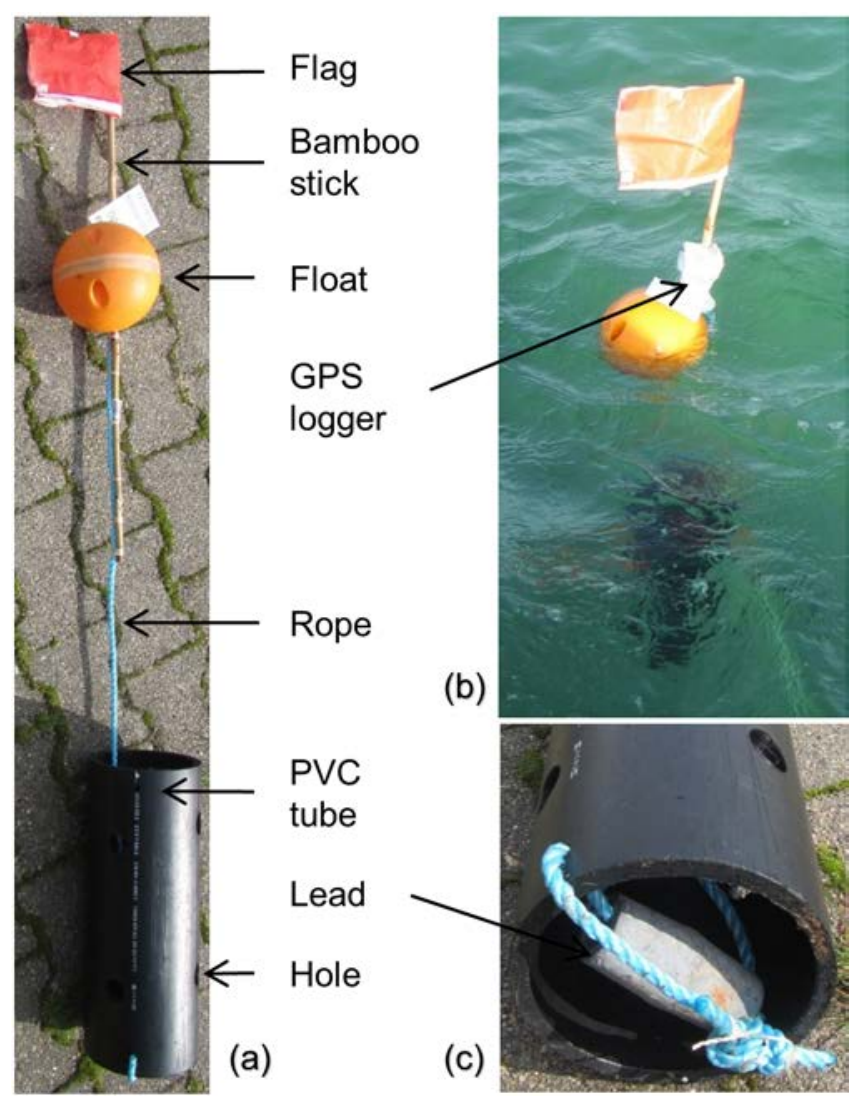

Fig. 5. Drifting device to measure current speed and direction with (a) full view of the device, (b) view of the device at sea, and (c) close-up view of the lower end of the PVC tube which allows to measure at the median net height in the water column. Two similar devices were left drifting between the nets during data collection. 
Back face: $X(10.0 \pm 0.0 \mathrm{~cm}, \mathrm{n}=35)$

Camera pair used for fleet...

Back face: $Z(10.0 \pm 0.0 \mathrm{~cm}, \mathrm{n}=32)$ Camera pair used for fleet...

Front face: $X(5.0 \pm 0.0 \mathrm{~cm}, \mathrm{n}=126)$ Camera pair used for fleet...

Front face: $Z(5.0 \pm 0.0 \mathrm{~cm}, \mathrm{n}=120)$ Camera pair used for fleet...

$Y(31.0 \pm 0.0 \mathrm{~cm}, \mathrm{n}=4)$ Camera pair used for fleet...
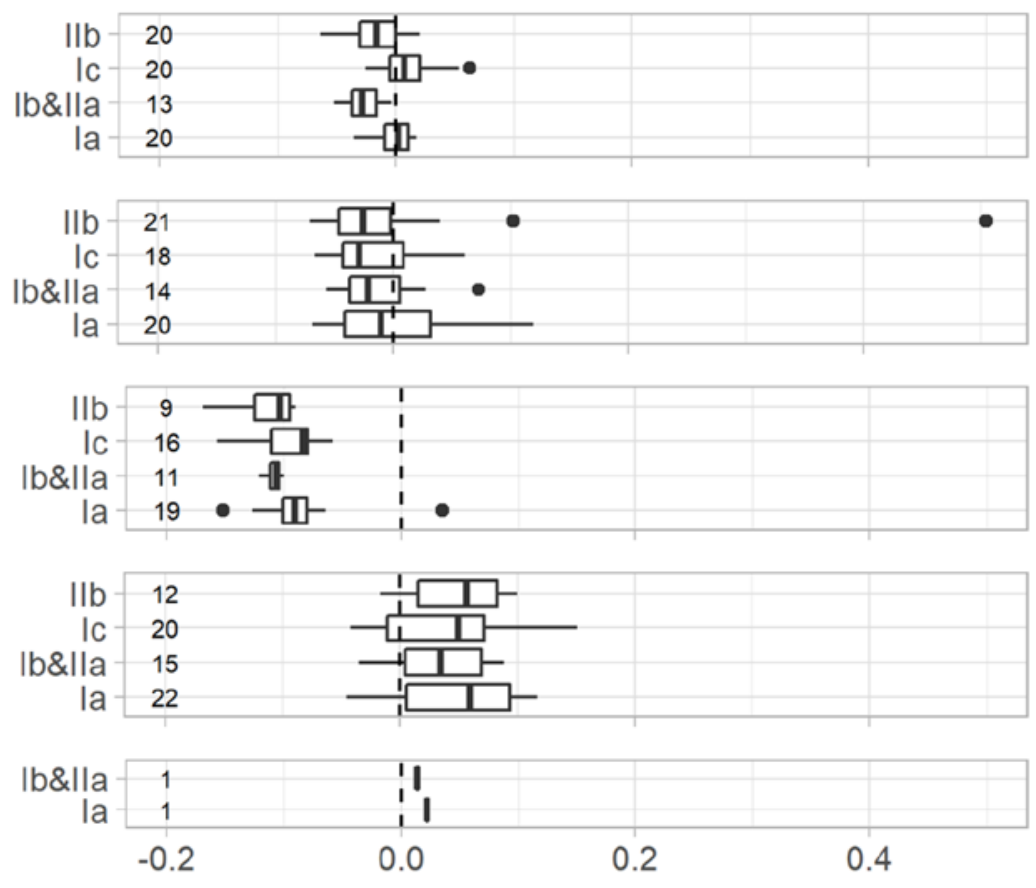

Relative difference

(a)

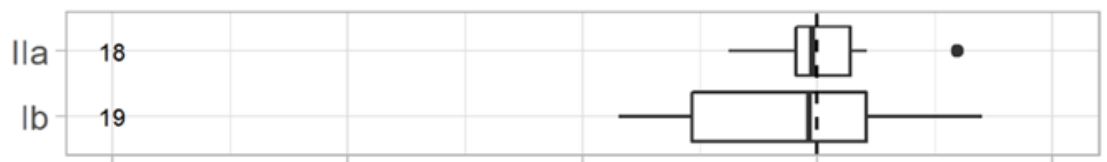

Heavy nets $(2.9 \pm 0.0 \mathrm{~cm}, \mathrm{n}=5)$

Fleet...

(b)

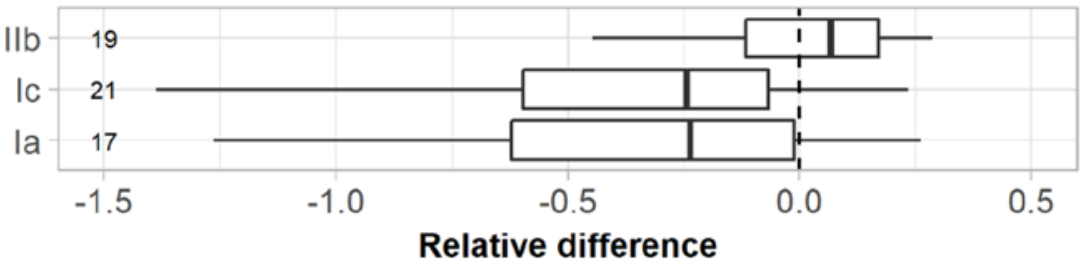

Fig. 6. (a) Relative difference of the calculated distances (with Vidsync) compared to the measured distances (with a measuring tape) between two nodes of the calibration frame on the back and front faces in the $\mathrm{X}$ (horizontal) and $\mathrm{Z}$ (vertical) dimensions, and between the back and front faces of the calibration frame (Y). (b) Relative difference of the calculated distances (with Vidsync) compared to the measured distances (with a measuring tape) between two coloured threads on the leadline of light and heavy bottom gillnets. On both (a) and (b), the horizontal 
dashed line stands for reference as no difference between measured and calculated. The distances measured are given as an average \pm standard deviation with $n$ the number of observations on the left of each plot. The number of the calculated distances used for the comparison is given on the right of each corresponding boxplot. 


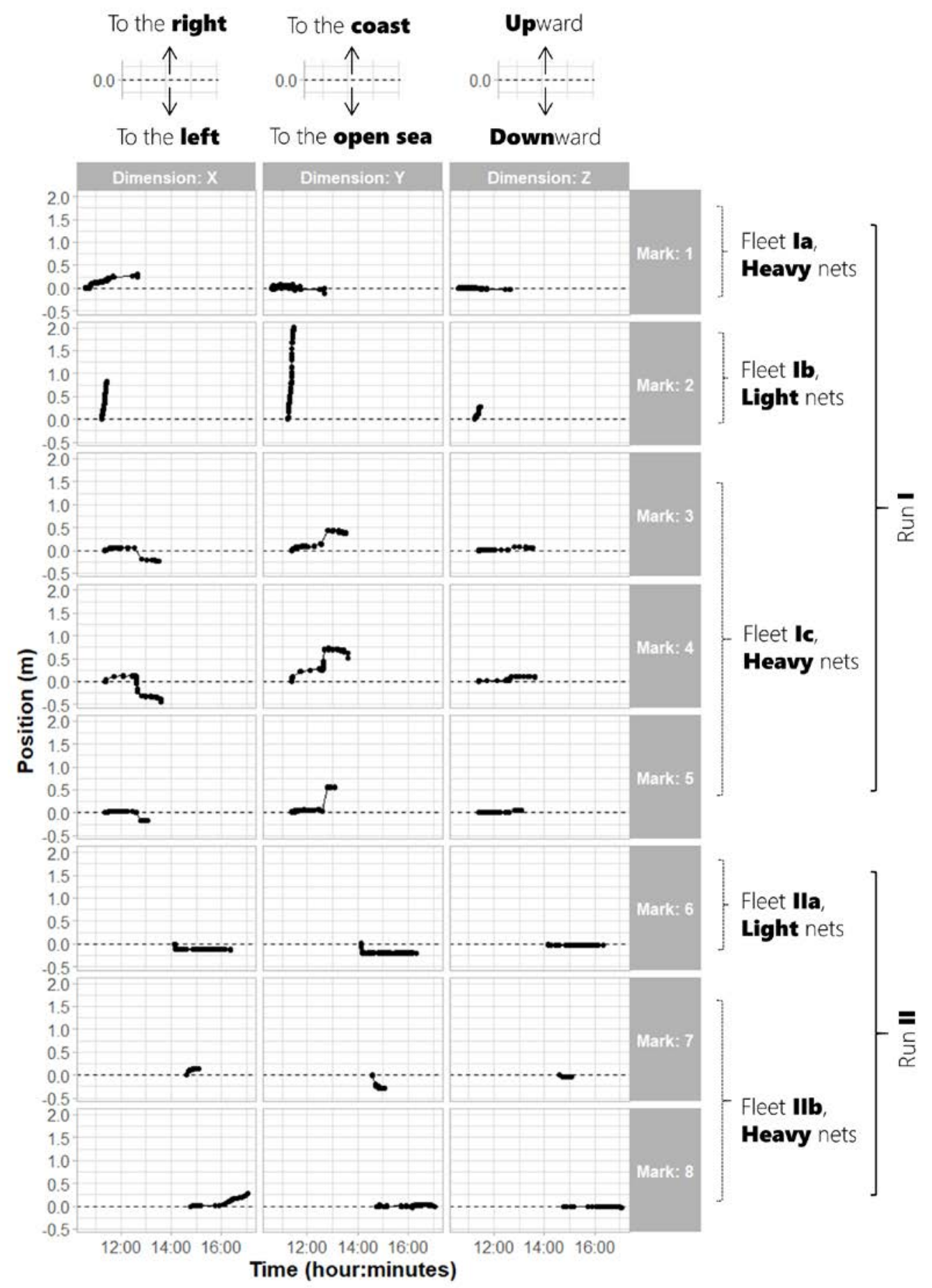

Fig. 7. Time plot of the relative position of the eight marks on the leadline of light and heavy gillnets observed in the pilot sea trial, in the $\mathrm{X}, \mathrm{Y}$ and $\mathrm{Z}$ dimensions. The relative position is given in $\mathrm{m}$ as the distance from the initial position (horizontal dashed line). Time is given as the real time of the day in hour:minutes. 

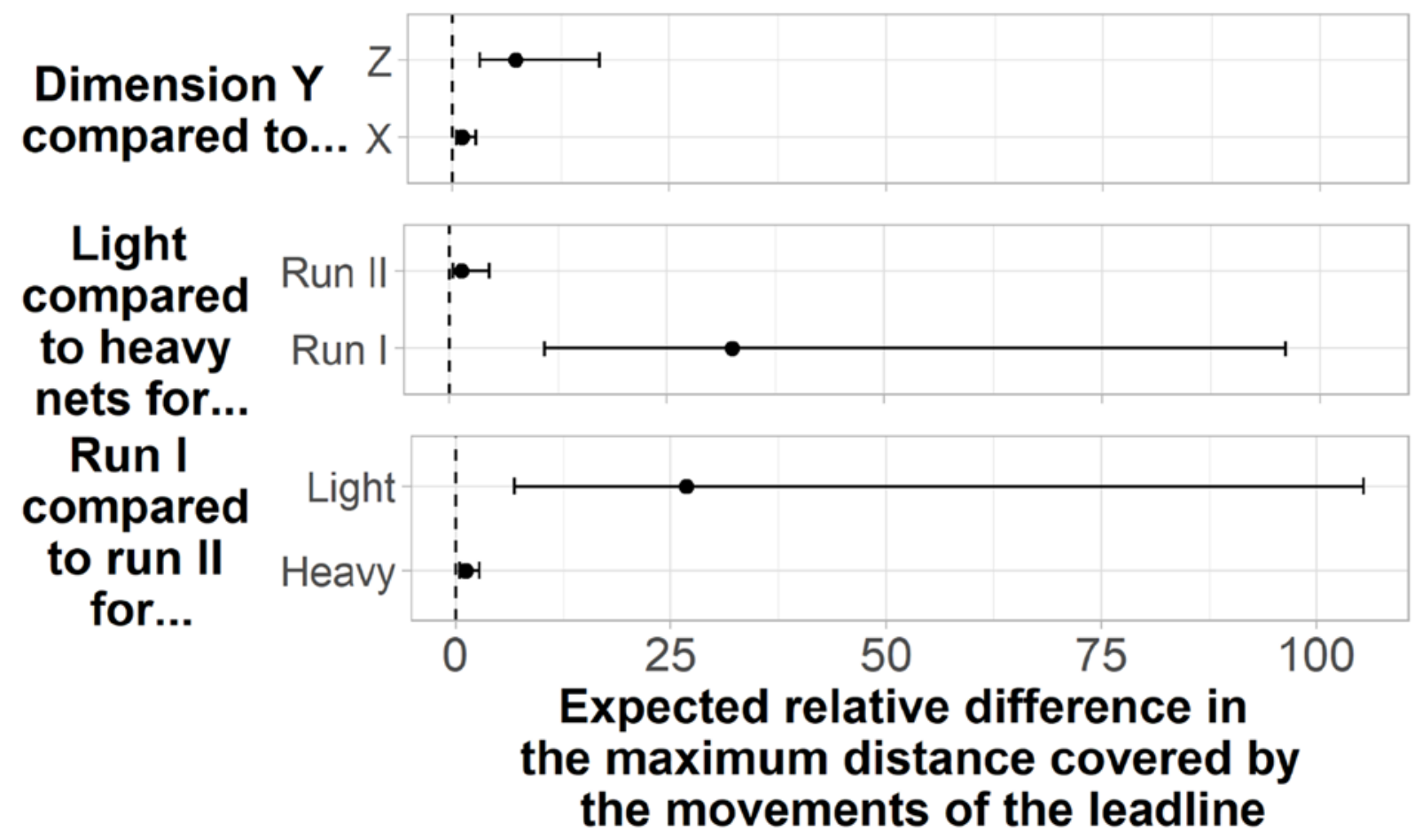

Fig. 8. Expected relative difference (95\% confidence limits) in the maximum distance covered by the movements of the leadline for the different experimental configurations. 